\title{
Setting priorities for child health and research: the neglected burden of injuries
}

\author{
Shanthi N Ameratunga, MBChB, MPH, PhD, (1) Adnan A Hyder, MD, MPH, PhD, (2) Shaheen Sultana, MBBS, MPH. ${ }^{(1)}$
}

\begin{abstract}
$\mathrm{A}$ vailable evidence provides a strong case for injury prevention in any child survival strategy. ${ }^{1,2}$ But whether this evidence informs priority-setting in child health programs or research is highly questionable. Injuries are a leading cause of death and disability among children after the first year of life. ${ }^{1,2}$ About $98 \%$ of these deaths are estimated to occur in low- and middle-income countries (LMICs) where injury prevention is an emerging field. ${ }^{3}$ Children warrant special consideration when addressing almost any type of injury as they are more vulnerable to forces on their body relative to adults, typically live in a world designed for adults, and are often unable to judge or circumvent the dangers inherent in many hazardous situations. ${ }^{4}$ Unsurprisingly, children from poor families are more exposed to unsafe environments and are disproportionately affected by injuries in most countries. ${ }^{4}$ In $A$ World Fit for Children -the outcome of a special session on children held by the UN General Assembly in 2002- the Plan of Action specifically charged the global community to "reduce child injuries due to accidents or other causes through development and implementation of appropriate preventive measures". ${ }^{5}$ Despite the acknowledged scale of the problem, global attention to childhood injuries in terms of public policies and resource investments remains disappointingly sluggish. ${ }^{4}$

The World Report on road traffic injury prevention published in $2004^{6}$ focussed unprecedented attention on the loss of young lives in road crashes. While there are
\end{abstract}

many effective interventions yet to be implemented, there is a robust evidence base supporting the need to do so. There are, however, many types of childhood injury that are less "visible" which are consequently destined to remain neglected public health issues. The lack of basic data results in a vicious cycle that limits opportunities to prioritise the required research to define the burden and determinants of childhood injury, overcome misconceptions and prejudices, and identify strategies for prevention. This problem became glaringly apparent when "childhood falls" was selected as a case study to test the application of a new methodology for setting priorities for global child health research. ${ }^{7}$ The project group working under the aegis of the Child Health \& Nutrition Research Initiative (CHNRI; www.chnri.org) electively avoided using road trauma as a case study given the 2004 World Report. In this regard, falls were expected have more in common with other childhood injuries that had not received exceptional levels of recent attention.

The best available evidence suggests that falls are an important cause of injury, often ranked as one of commonest reasons for emergency room visits in childhood and $1^{\text {st }}$ among the injury-specific causes. ${ }^{3,8}$ While we despair of the lack of reliable data on injury deaths from LMICs, information regarding non-fatal outcomes following falls, particularly those resulting in disabling consequences, is virtually non-existent in most low-income countries. ${ }^{9}$ The ability to reliably estimate the extent

(I) School of Population Health, Faculty of Medical \& Health Sciences, University of Auckland. Auckland, New Zealand.

(2) Departments of International Health, and Health Policy \& Management, Center for Injury Research \& Policy, and Berman Institute of Bioethics, Johns Hopkins University Bloomberg School of Public Health. Baltimore, MD, USA.

Address reprint requests to: Shanthi Ameratunga. Section of Epidemiology \& Biostatistics, School of Population Health, Faculty of Medical \& Health Sciences, University of Auckland. Private Bag 92019,Auckland, New Zealand. 
to which a given intervention can reduce the burden of falls -an important factor in priority-setting-is therefore highly compromised.

This gap in information is compounded by scant knowledge of the context of falls in LMICs (e.g. relevant exposures and risk factors). Reports and presentations at the 2006 World Conference on Injury Prevention suggest that falls from heights in and around traditional homes, from rooftops, trees and environmental structures, and when riding animals are substantially under-appreciated risks in these settings. ${ }^{8}$ Over 25 years ago, researchers developing an intervention to prevent playground injuries in New York noted the importance of understanding and addressing the variety of injury mechanisms and the unstructured environments in which most events occur. ${ }^{10}$ If childhood injury prevention in LMICs is to be considered seriously, the same principles apply.

An examination of the evidence base for strategies that could prevent fall-related injuries in children aged less than five years identified several studies that investigated the effects of home-safety education, massmedia- and community-based education, free-distribution of safety equipment, home visiting programs, and the provision of incentives in high-income countries. ${ }^{11-22}$ The research evidence supporting strategies to prevent falls among pre-schoolers in high-income countries (e.g., standards and legislation relating to balconies, windows, nursery furniture, baby-walkers, and playgrounds; home visiting programmes ${ }^{23-28}$ has no parallel in LMIC settings where the vast majority of injuries occur. A recent review concluded that apart from general recommendations about increasing supervision of children, reducing the height of equipment, and ensuring appropriate ground surfacing of playgrounds, the "Children Can't Fly Program"21 (a community-based program aimed at reducing the incidence of falls from high rise windows in the United States) was the only effective intervention which could be considered applicable to LMICs. ${ }^{8}$

This grossly inadequate knowledge cannot effectively inform priority-setting in a global context for a variety of purposes -whether this be improving the efficiency of existing strategies; adapting and transferring technology from other contexts, developing new interventions; or a mix of these and other approaches. In this effort to inform the application of a priority setting methodology for CHNRI, it was clear that in contrast to other threats to child health (e.g., malaria, diarrhoea, acute lower respiratory infections, and birth asphyxia); there was a need for basic epidemiological data regarding the occurrence, risks, and strategies to prevent childhood falls in LMICs.
Despite these limitations, 'childhood falls' as a case study provided useful insights for the priority setting methodology. It stimulated a broader notion of the term "intervention" that was not limited to traditional biomedical and health sector domains. Environmental planning, engineering design, enforcement and educational strategies have reduced many types of childhood injury. ${ }^{8}$ Strategies to prevent falls in LMICs could include context-relevant building codes and targeted measures to mitigate specific hazards. As with other childhood injuries, addressing broader socio-economic determinants are likely to be vital to limit increasing disparities.

These issues are not unique to falls but they epitomise concerns that attention to preventing childhood injuries lags efforts to control disease risks in many dimensions, including research investments. ${ }^{4}$ The decision by the World Health Organization to release a world report on child injuries in 2008 must spur efforts to form global partnerships that stimulate research to strengthen the evidence base and act where this is most needed. Governments, donor agencies and health professionals in rich and poor countries should consider injuries, like falls, a serious risk to child health and welfare, and initiate focused efforts at prevention and control.

\section{References}

I. Hyder AA, Arifeen S, Begum N, Fishman S, Wali S, Baqui AH. Death from drowning: defining a new challenge for child survival in Bangladesh. Inj Control Saf Promot 2003; 10(4):205-2।0.

2. Peden $M$, McGee K, E K, eds. Injury: a leading cause of the global burden of disease, 2000. Geneva:World Health Organization, 2002.

3. World Health Organization. Child injury prevention: Proceedings of a WHO consultative meeting to develop a global child injury prevention strategy. Geneva:World Health Organization, 2005.

4. United Nations Children's Fund (UNICEF), World Health Organization. Child and adolescent injury prevention: a global call to action. Geneva: World Health Organization, 2005.

5. United Nations Children's Fund (UNICEF).A World Fit for Children. New York: UNICEF, 2003.

6. Peden M, Scurfield R, Sleet D, Mohan D, Hyder AA, Jarawan E, et al., eds. World report on road traffic injury prevention. Geneva, Switzerland: World Health Organisation, 2004.

7. Child Health \& Nutrition Research Initiative (CHNRI). Proceedings from the Workshop on Setting priorities for child health research. Forum 10. Global Forum for Health Research; 2006 oct 29; Cairo, Egypt. 8. Norton R, Hyder A, Bishai D, Peden M. Unintentional Injuries. In: Jamison D, Breman J, Measham A,Alleyne G, Claeson M, Evans D, et al., eds. Disease Control Priorities in Developing Countries. 2nd ed.Washington, DC: Oxford University Press and The World Bank, 2006:737-754. 9. Barss P, Smith G, Baker S, Mohan D. Injury Prevention: An International Perspective. Epidemiology, Surveillance, and Policy. Oxford: Oxford University Press, 1998.

10. Fisher L, Harris VG, VanBuren J, Quinn J, DeMaio A. Assessment of a pilot child playground injury prevention project in New York State.Am J Public Health 1980;70(9): 1000-1002. 
I I. Clamp M, Kendrick D.A randomised controlled trial of general practitioner safety advice for families with children under 5 years. BMJ 1998;316(7| 144):1576-1579.

12. Conners GP,Veenema TG, Kavanagh CA, Ricci J, Callahan CM. Still falling: a community-wide infant walker injury prevention initiative. Patient Educ Couns 2002;46(3): 169- 173.

13. Ferrari JR, Baldwin CH. From cars to carts. Increasing safety belt usage in shopping carts. Behavior Modification 1989;13(I):51-64.

I4. Ferrari JR, Baldwin CH. Promoting Safety Belt Use in Shopping Carts: buckle up your baby. Environ Behav 1989;21(5):603-619.

15. Guyer B, Gallagher SS, Chang BH, Azzara CV, Cupples LA, Colton T. Prevention of childhood injuries: evaluation of the Statewide Childhood Injury Prevention Program (SCIPP). Am J Public Health 1989;79(I I): |52|-|527.

16. King WJ, Klassen TP, LeBlanc J, Bernard-Bonnin AC, Robitaille Y, Pham $B$, et al.The effectiveness of a home visit to prevent childhood injury. Pediatrics 200I;108(2):382-328.

17. King WJ, LeBlanc JC, Barrowman NJ, Klassen TP, Bernard-Bonnin AC, Robitaille Y, et al. Long term effects of a home visit to prevent childhood injury: three year follow up of a randomized trial. Inj Prev 2005; I (2): 106-109.

18. Lindqvist K, Timpka T, Schelp L, Risto O. Evaluation of a child safety program based on the WHO safe community model. Inj Prev 2002;8(I):23-26.

19. Posner JC, Hawkins LA, Garcia-Espana F, Durbin DR.A randomized, clinical trial of a home safety intervention based in an emergency department setting. Pediatrics 2004; I 13(6): 1603-1608.

20. Smith GA. Improving safety-restraint use by children in shopping carts: evaluation of a store-based safety intervention. Pediatrics 2006; I I8(2):739-745.
21. Spiegel CN, Lindaman FC. Children can't fly: a program to prevent childhood morbidity and mortality from window falls. Am J Public Health | 977;67(I2): I |43-I | 47.

22. Watson M, Kendrick D, Coupland C, Woods A, Futers D, Robinson J. Providing child safety equipment to prevent injuries: randomised controlled trial. BMJ 2005;330(7484): 178.

23. McClure R, Nixon J, Spinks A, Turner C. Community-based programmes to prevent falls in children: a systematic review.J Paediatr Child Health 2005;4I(9-10):465-470.

24. Committee on Injury and Poison Prevention. American Academy of Pediatrics: Falls from heights: windows, roofs, and balconies. Pediatrics 200 I; I07(5): I I88-I I9I.

25. American Academy of Pediatrics, Committee on Injury and Poison Prevention. Injuries associated with infant walkers. Pediatrics 200I;108(3):790-792.

26. Roberts I, Kramer MS, Suissa S. Does home visiting prevent childhood injury? A systematic review of randomised controlled trials. BMJ 1996;312(7022):29-33.

27. MacKay M,Vincenten J, Brussoni M,Towner L. Child Safety Good Practice Guide: Good investments in unintentional child injury prevention and safety promotion. Amsterdam: European Child Safety Alliance, EuroSafe, 2006.

28. Dowswell T, Towner E, Cryer C, Jarvis S, Edwards P, Lowe P.Accidental falls: fatalities and injuries. An examination of the data sources and review of the literature on preventive strategies: University of Newcastle upon Tyne, 1999. 